\title{
Dentigerous Cyst Associated with an Ectopic Tooth in the Subcondylar Area: A Case Report and Literature Review
}

\author{
Mehmet Melih Ömezli ${ }^{1}$, Ferhat Ayranci ${ }^{1}$, Hale Yurtyapan $^{1}$, Nurcan Salman ${ }^{2}$ \\ ${ }^{1}$ Department of Oral and Maxillofacial Surgery, Faculty of Dentistry, Ordu University, 52100, Ordu, Turkey \\ ${ }^{2}$ Department of Pathology, Ministry of Health, 52100, Ordu, Turkey
}

Received: 02 June 2015 accepted: 15 July 2015/ published online: 30 August 2015

(c) Ordu University Institute of Health Science, Turkey, 2015

\begin{abstract}
Dentigerous cysts associated with an ectopic third molar in the subcondylar area are fairly rare, and information is limited about its causes and characteristics. This article reports a case of dentigerous cysts associated with an ectopic third molar in the subcondylar and reviews the literature on the clinical signs and symptoms and different treatment methods of this condition.

We report a case dentigerous cyst associated with an ectopic mandibular third molar in the subcondylar area. 14 cases of dentigerous cysts associated with an ectopic third molar in the subcondylar area reported in the English-language literature over the past 30 years, identified from Medline databases are also reviewed.

We found a mean age at diagnosis of 48.1 years and a higher prevalence in women. Facial pain and swelling on the preauricular region or ipsilateral side of the mandible were the most common symptoms. Among the 14 case reports identified, 7 were by an extraoral approach and 7 were by an intraoral approach. The most commonly used extra-oral approaches are retromandibular.

The etiology of ectopic mandibular third molars has not yet been completely clarified. They must be removed if they cause symptoms or are associated with cystic pathology. The treatment of third molars in the condylar region is divided into conservative and, in most cases, surgical removal by intra or extra-oral route. The surgical approach must be carefully planned according to the location and position of ectopic third molars.
\end{abstract}

Key words: Dentigerous, subcondylar, ectopic tooth.

Address for correspondence/reprints:

Mehmet Melih Ömezli

E-mail address: mmelihomezli@hotmail.com

*This case report was presented at the ACBID-BAOMS Joint Congress in conjuction with $4^{\text {th }}$ conference of BAMFS, 113, Istanbul, 2014.

DOI: 10.19127/mbsjohs.99919

\section{Introduction}

Ectopic teeth are those that are impacted in unusual positions or have been displaced and are at a distance from their normal anatomic location (Shivashankara et al., 2012). The reason as to why third molars are ectopically placed is still unclear. However, ectopic eruption may result owing to one of the following 3 processes: developmental disturbance, iatrogenic activity, or pathologic process, such as a tumor or a cyst (Buyukkurt et al., 2010; Shivashankara et al., 2012; Lambade et al., 2013). 
Dentigerous cysts, also called follicular cyst, are the most common developmental odontogenic cysts, and second most common cystic lesions of the jaw next to radicular cysts (Kocer et al., 2002; McCrea, 2009). They account for approximately $24 \%$ of all true cysts in the jaw (McCrea, 2009). These cysts are caused by the expansion of dental follicles, which result from accumulation of fluid between the tooth crown and epithelial components (Edamatsu et al., 2005). The mandible is likely to be the primarily affected site, as cysts are located in the mandible in $75 \%$ of the cases (Ustuner et al., 2003). These cysts most commonly arise from mandibular third molars, followed by maxillary third molars and maxillary canines (Kocer et al., 2002; Buyukkurt et al., 2010). Clinical examinations reveal a missing tooth or teeth and an asymptomatic swelling that sometimes results in facial asymmetry and possible pathologic fracture (Kocer et al., 2002; McCrea, 2009). Dentigerous cysts surrounding impacted teeth often displace these teeth into ectopic positions (McCrea, 2009; Buyukkurt et al., 2010). The degree of displacement may be dramatic. It has been reported that mandibular third molars may be moved to the ramus, condylar, or coronoid regions or to the inferior cortex of the mandible (McCrea, 2009; Kim, 2011).

The standard treatment for a dentigerous cyst is enucleation and extraction of the tooth involved (Martinez-Perez and Varela-Morales, 2001; Kocer et al., 2002; Buyukkurt et al., 2010; Bowman et al., 2014). In large cysts, an initial marsupialization to diminish the size of the osseous defect followed by enucleation and tooth extraction has been advocated (Martinez-Perez and Varela-Morales, 2001).

However, treatment of ectopic third molars associated with dentigerous cysts in the condylar region are recommended to prevent the morbidity caused by infection of a cyst, the malfunction of the temporomandibular joint, and the risk of fracture in an area where the bone is thin (Salmeron et al., 2008; Kim, 2011).

In the present paper, we report the case of dentigerous cysts associated with an ectopic tooth in the subcondylar area and review the literature reports of this condition over the past 30 years. A search of Medline from 1984 to 2014 using the key words "dentigerous cyst," "ectopic tooth," "subcondylar," and "ectopic third molar and mandibular condyle" was conducted.

\section{Case}

A 52-year-old woman was referred due to pain, swelling, and episodic purulent intraoral secretion through the retromolar region for about 3 months. She had no other visual complaints. On general examination, the patient was apparently healthy with no significant past medical history. Physical intraoral examination revealed a swelling overlying the left condylar area with purulent secretion and an absence of the left mandibular third molar. The gingival and alveolar mucosa covering the lesion was normal. Extra-oral examination did not reveal any swelling or symptoms.

Panoramic radiography revealed a large, welldefined radiolucency surrounding the crown of a deeply impacted left mandibular third molar at the subcondylar area (Fig 1) and Computed Tomography (CT) confirmed a well-defined unilocular radiolucent lesion which is related to an unerupted mandibular molar and close anatomical relationship between the molar roots, cyst, and the mandibular canal and also confirmed lingual cortex destruction through on the left ramus (Fig 2a,2b). Based on clinical and radiological findings dentigerous cyst, radicular cyst, fibrous dysplasia, and ameloblastoma were suspected.

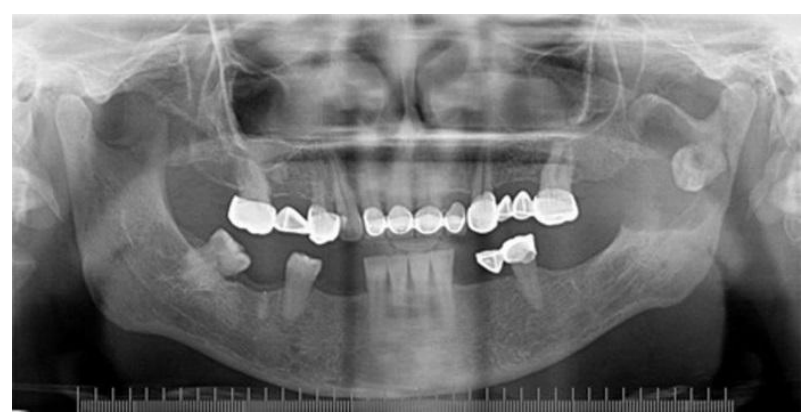

Figure 1: The panoramic radiography showing dentigerous cyst associated with an ectopic third molar in the subcondylar region.

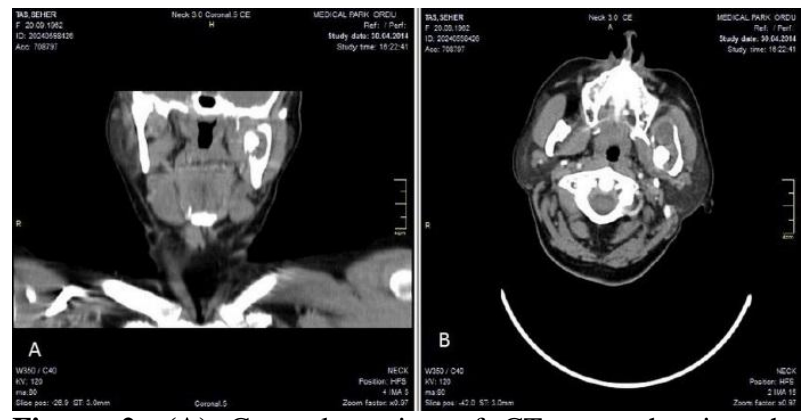

Figure 2: (A) Coronal section of CT scan showing the downward crown position of the ectopic third molar with the proximity to the internal cortical bone of the mandible. (B) Axial section of CT scan showing the ectopic third molar. 
Surgical removal of the cyst under general anesthesia was planned. After informing the patient of all possible complications that can occur during and after the surgery, a signed consent form was obtained from the patient. After endotracheal intubation, local anesthesia was injected (Ultracaine-DS Forte, Aventis/ Turkey) and an intraoral incision was performed from the molar area to the ramus and retromolar area and the mucoperiosteal flap was raised. The cyst capsule was dissected carefully from the inferior alveolar nerve and the ectopic impacted third molar was removed (Fig 3). After placing a drain, primary mucosal closure was achieved.

The patient was prescribed postoperative antibiotics (Amoxicillin /Clavulanic Acid and Ornidazole), analgesic (Paracetamole), and mouthwash (Chlorhexidine Gluconate/ Benzydamine Hydrochloride) for five days and adviced to remain on a soft and liquid diet for four weeks.

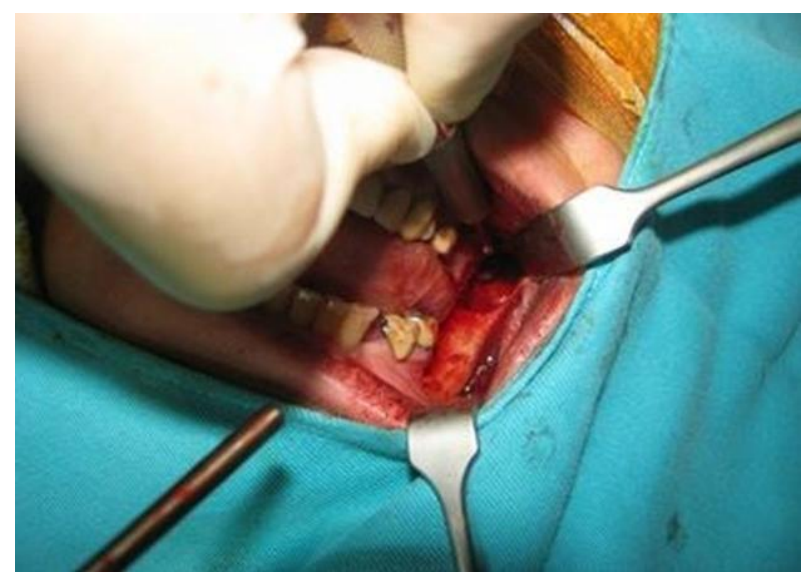

Figure 3. Intraoperative photograph.

The specimens were sent out for histopathologic examination. The pathology report confirmed the diagnosis was a dentigerous cyst, showing a thin, fibrous wall lined by two to three layers of flat epithelial cells resembling reduced enamel epithelium. The connective tissue showed slight inflammatory infiltrate (Fig 4).

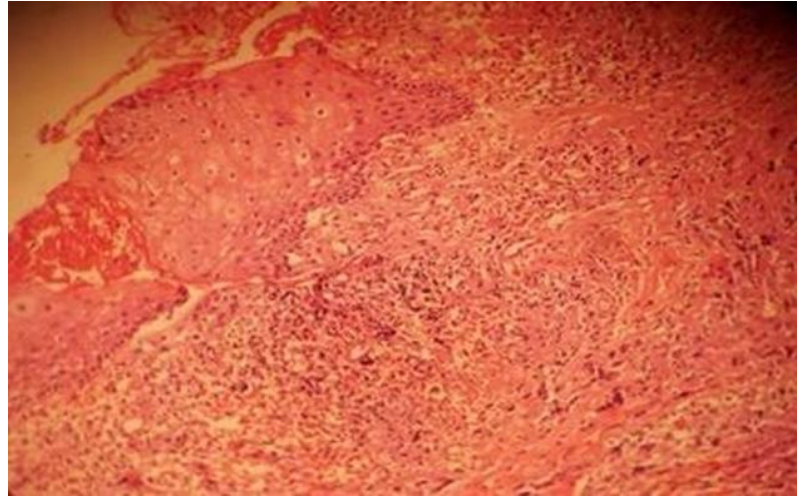

Figure 4. Histopathologically, cyst was lined by keratinized squamous epithelium.

On the second day following surgery, the drain was taken out and on the seventh day the sutures were removed. The patient was non-symptomatic and there was no postoperative condylar fracture or paresthesia (Fig 5). The patient is checked in regularly visits.

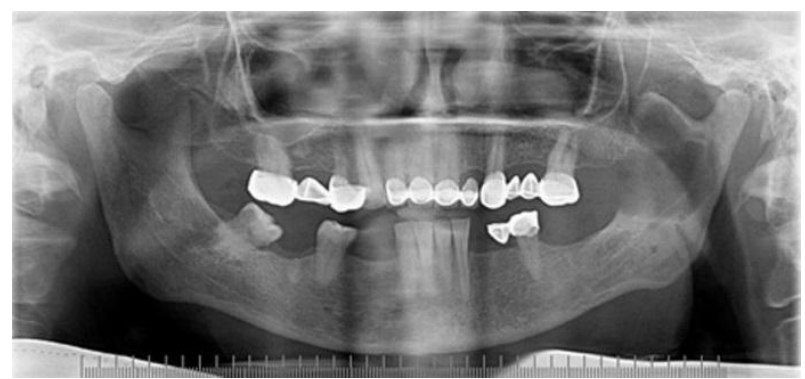

Figure 5: Postoperative panoramic radiography

\section{Discussion}

Ectopic teeth are those that are impacted in unusual positions or that have been displaced and are at a distance from their normal anatomic location (Iglesias-Martin et al., 2012; Lambade et al., 2013) and have been reported in the mandibular condyle, coronoid process, orbit, palate, nasal cavity, floor of mouth, and maxillary sinüs (Buyukkurt et al., 2010; Pace et al., 2010; Shivashankara et al., 2012; Lambade et al., 2013). The etiology of an ectopic tooth has not yet been completely clarified. However, an ectopic eruption may result due to either developmental disturbances, iatrogenic activity, or pathological process such as dentigerous cysts (Pace et al., 2010; Buyukkurt et al., 2010; Shivashankara et al., 2012; Iglesias-Martin et al., 2012). Dentigerous cysts are the second most common odontogenic cysts after radicular cysts, accounting for approximately $24 \%$ of all true cysts of the jaw and are the most common developmental cyst of the 
jaw (Kocer et al., 2002; McCrea, 2009). The third molar is the tooth most frequently involved and the posterior area of the mandible is the most common site of dentigerous cysts (Kocer et al., 2002; Ustuner et al., 2003). However, dentigerous cysts associated with an ectopic tooth in the subcondylar region are very rare and, as far as we could determine, only 14 cases had been reported since 1984 (Table I).

Dentigerous cysts are benign odontogenic lesions arising from the completed crown of impacted, embedded, or unerupted teeth (MartinezPerez and Varela-Morales, 2001; Kocer et al., 2002). They are more prevalent in males and are most common in the second or third decade of life, and are rarely seen during childhood (Ustuner et al., 2003). However, among the 14 cases reported in the present study (Table 1), we found a higher prevalence in women, including 8 cases. The mean age was 48.1 years. The age of these patients ranged from 30 to 68 years old.

Diagnosis is based on clinical findings together with imaging tests, mainly panoramic radiograph and CT. Pace et al. reported that a panoramic radiography together with a clinical examination is usually sufficient for diagnosis of an ectopic third molar (Pace et al., 2010). However, CT scans are sometimes required to determine a more precise anatomical position and its relation to adjacent structures. On radiographic examinations, dentigerous cysts appear as unilocular lucent cysts of varying sizes, with well-defined sclerotic borders, associated with the crown of an impacted tooth (Ustuner et al., 2003; McCrea, 2009;).

Dentigerous cysts are typically asymptomatic. These lesions progress slowly and are usually painless, but may cause facial swelling and delayed tooth eruption (Kocer et al., 2002; Ustuner et al., 2003; Buyukkurt et al., 2010). Among the 14 case reports summarized in Table I, the most common signs and symptoms associated with ectopic teeth are facial pain (Medici et al., 2001; Tumer et al.,2002; Suarez-Cunqueiro et al., 2003; Wang et al., 2008; Salmeron et al., 2008; Gadre and Waknis, 2010; Iglesias-Martin et al., 2012), facial swelling on the preauricular region or ipsilateral side of the mandible (Tumer et al.,2002; SuarezCunqueiro et al., 2003; Salmeron et al., 2008; Pace et al., 2010; Gadre and Waknis, 2010; Scott et al., 2012; Iglesias-Martin et al., 2012; Bowman et al.,2014) and trismus (Wassouf et al., 2003; Salmeron et al., 2008; Iglesias-Martin et al., 2012), difficulty in mastication (Bux and Lisco, 1994;
Medici et al., 2001). In 3 of the 14 summarized patients, intraoral or extraoral drainage of purulent material have been reported (Salmeron et al., 2008; Pace et al., 2010; Gadre and Waknis, 2010). Enucleation has been the standard treatment for dentigerous cysts, along with extraction of the associated tooth (Buyukkurt et al., 2010). However, the surgical removal of an ectopic mandibular third molar with acute inflammation or cystic lesions is recommended to prevent further complications, such as diffuse osteolysis, condylar process deformity or weakening of the bone predisposing to fracture (Medici et al., 2001; Gadre and Waknis, 2010; Kim, 2011).

In the treatment of ectopic third molars in the condylar region, several approaches have been used, including an intra-oral approach (Medici et al., 2001; Wassouf et al., 2003; Wang et al., 2008; Gadre and Waknis, 2010; Scott et al., 2012;) an endoscopic intraoral approach (Suarez-Cunqueiro et al., 2003) and an extra-oral approach (Bux and Lisco, 1994; Tumer et al.,2002; Salmeron et al., 2008; Pace et al., 2010; Iglesias-Martin et al., 2012; Bowman et al.,2014). Among the 14 cases summarized in Table I, 7 (Bux and Lisco, 1994; Tumer et al., 2002; Salmeron et al., 2008; Pace et al., 2010; Iglesias-Martin et al., 2012; Bowman et al., 2014) were by an extraoral approach and 7 (Medici et al., 2001; Wassouf et al., 2003; Wang et al., 2008; Gadre and Waknis, 2010; Scott et al., 2012;) were by an intraoral approach. The most commonly used extra-oral approaches are retromandibular (Bux and Lisco, 1994; Pace et al., 2010; Iglesias-Martin et al., 2012) and preauricular (Tumer et al.,2002; Salmeron et al., 2008). These external approaches have the advantage of good surgical exposure, especially to the body and ascending ramus, to the condylar region, but may result in complications such as cutaneous scar formation, damage of temporomandibular joint components, facial nerve injury in the case of pre-auricular access, or damage of the marginal mandibular branch of the seventh cranial nerve (Medici et al., 2001; Wang et al., 2008; Sanghera and Jones, 2013). However, Bowman et al. reported that the transmasseteric antero-parotid Approach (TMAP) reduced the surgical morbidity anticipated with alternative approaches, as it has a low risk of iatrogenic injury to the facial nerve and also reduces the risk of injury to the lingual nerve (Bowman et al., 2014). Although it provides a smaller surgical site, the intra-oral approach helps in avoiding a visible 
facial scar and injury to the facial nerve (Wang et al., 2008; Iglesias-Martin et al., 2012; Sanghera and Jones, 2013). The intraoral approach is, therefore, preferable in order to avoid visible scars and facial nerve injury, while the others are secondary options if necessary (Wassouf et al., 2003; Gadre and Waknis, 2010). Therefore, we also chose this method for our case.

\begin{tabular}{|c|c|c|c|c|c|}
\hline Author/year & Age & Gender & Side & Symptom & Treatment \\
\hline Bux and Lisco, 1994 & 66 & Female & Right & $\begin{array}{c}\text { Trismus } \\
\text { Fever } \\
\text { Difficulty in Mastication }\end{array}$ & $\begin{array}{l}\text { Retromandibular } \\
\text { Approach }\end{array}$ \\
\hline Medici et al, 2001 & 41 & Female & Right & $\begin{array}{l}\text { Pain and Swelling in the Preauricular Region } \\
\text { Difficulty in Mastication }\end{array}$ & Intraoral Approach \\
\hline Tumer et al, 2002 & 47 & Male & Right & $\begin{array}{c}\text { Facial Pain } \\
\text { Facial Swelling }\end{array}$ & Preauricular Approach \\
\hline Wassouf et al, 2003 & 49 & Female & Left & Submandibular and Masseter Space Abscess & Intraoral Approach \\
\hline $\begin{array}{l}\text { Suarez-Cunqueiro et } \\
\text { al, } 2003\end{array}$ & 45 & Male & Right & $\begin{array}{c}\text { Facial Pain } \\
\text { Facial Swelling }\end{array}$ & Endoscopic Approach \\
\hline Salmeron et al, 2008 & 53 & Female & Right & $\begin{array}{c}\text { Limitation of Mouth Opening } \\
\text { Facial Pain } \\
\end{array}$ & Endaural Approach \\
\hline Salmeron et al, 2008 & 41 & Male & Left & $\begin{array}{c}\text { Hard Swelling with Pain } \\
\text { Episodic Purulent Intraoral Secretion }\end{array}$ & Preauricular Approach \\
\hline Wang et al, 2008 & 31 & Female & Right & $\begin{array}{c}\text { Facial Pain } \\
\text { Facial Swelling }\end{array}$ & Intraoral Approach \\
\hline $\begin{array}{l}\text { Gadre and Waknis, } \\
2009\end{array}$ & 30 & Female & Right & $\begin{array}{c}\text { Facial Pain } \\
\text { Facial Swelling }\end{array}$ & Intraoral Approach \\
\hline $\begin{array}{l}\text { Gadre and Waknis, } \\
2009\end{array}$ & 40 & Male & Left & $\begin{array}{c}\text { Facial Pain } \\
\text { Facial Swelling } \\
\text { Purulent Discharge }\end{array}$ & Intraoral Approach \\
\hline Pace et al, 2010 & 53 & Male & Right & $\begin{array}{c}\text { Skin Sweelling } \\
\text { Discharged From Skin Lesion }\end{array}$ & $\begin{array}{l}\text { Retromandibular } \\
\text { Approach }\end{array}$ \\
\hline Martinet al, 2012 & 53 & Female & Left & $\begin{array}{l}\text { Intense Pain And Swelling in the Preauricular } \\
\text { Region } \\
\text { TrismusApproach }\end{array}$ & $\begin{array}{c}\text { Retromandibular } \\
\text { Approach }\end{array}$ \\
\hline Bowman et al, 2014 & 56 & Male & Right & Preauricular Swelling & $\begin{array}{l}\text { Transmasseteric antero- } \\
\text { parotid Approach }\end{array}$ \\
\hline & 68 & Female & Left & or Region & Intraoral \\
\hline
\end{tabular}

In order to treat dentigerous cysts associated with ectopic third molars in mandibular condyle, the Endoscopic approach should be used when is not approached due to the limited surgical field and the poor visualization in inaccessible anatomical regions. The use of this method has considerable advantages, such as good illumination, clear and magnified visualization of the operating field and as a result, a more conservative surgery with precise dissection (Suarez-Cunqueiro et al., 2003). In certain situations endoscopic removal is possible; however it is not preferred in some cases because of the difficulty that would be encountered in sectioning and removing the tooth and ensuring complete removal of all cystic material (Pace et al., 2010).

\section{Conclusion}

A dentigerous cyst associated with an ectopic third molar in the subcondylar area is fairly rare. In the literature, 14 cases had been reported since 1984. However, the true incidence is still unknown. The incidence seems to be higher in women and fourth decades, as in other studies. Ectopic third molars must be removed if they cause symptoms or are associated with cystic pathology. The treatment of third molars in the condylar region is divided into conservative and, in most cases, surgical removal by intra or extra-oral route. The surgical approach must be carefully planned according to the location and position of ectopic third molars.

Informed Consent: Written informed consent was obtained from patients who participated in this study.

Peer-review: Externally peer-reviewed.

Author Contributions: Concept MMO, FA; DesignMMO; Supervision MMO, FA; Data Collection and/or Processing MMO, HY; Analysis and/or Interpretation MMO, NS; Literature Review MMO; Writing MMO, HY; Critical Review MMO

Conflict of Interest: No conflict of interest was declared by the authors.

Financial Disclosure: The authors declared that this study hasn't received no financial support.

\section{References}

Bowman J, O'Regan B, Bhopal S. Transmasseteric antero-parotid approach: a technique adaptation for ectopic subcondylar third molar removal and associated dentigerous cyst enucleation. $\mathrm{Br}$ J Oral Maxillofac Surg 2014;52(1):e7-8.

Bux P, Lisco V. Ectopic third molar associated with a dentigerous cyst in the subcondylar region: report of case. J Oral Maxillofac Surg 1994;52(6):630-2.

Buyukkurt MC, Omezli MM, Miloglu O. Dentigerous cyst associated with an ectopic tooth in the maxillary sinus: a report of 3 cases and review of the literature. Oral Surg Oral Med Oral Pathol Oral Radiol Endod 2010;109(1):67-71.

Edamatsu M, Kumamoto H, Ooya K, Echigo S. Apoptosis-related factors in the epithelial components of dental follicles and dentigerous cysts associated with impacted third molars of the mandible. Oral Surg Oral Med Oral Pathol Oral Radiol Endod 2005;99(1):17-23.

Gadre KS, Waknis P. Intra-oral removal of ectopic third molar in the mandibular condyle. Int $\mathbf{J}$ Oral Maxillofac Surg 2010;39(3):294-6.

Iglesias-Martin F, Infante-Cossio P, TorresCarranza E, Prats-Golczer VE, Garcia-PerlaGarcia A. Ectopic third molar in the mandibular condyle: a review of the literature. Med Oral Patol Oral Cir Bucal 2012;17(6):e1013-7. 
Kim JS. Cone beam computed tomography findings of ectopic mandibular third molar in the mandibular condyle: report of a case. Imaging Sci Dent 2011;41(3):135-7.

Kocer U, Aksoy HM, Tiftikcioglu YO, Ertoy D, Karaaslan O. Giant dentigerous cyst occupying the right hemimandible. Can J Plast Surg 2002;10(4):171-4.

Lambade P, Lambade D, Dolas RS, Virani N. Ectopic mandibular third molar leading to osteomyelitis of condyle: a case report with literature review. Oral Maxillofac Surg 2013;17(2):127-30.

Martinez-Perez D, Varela-Morales M. Conservative treatment of dentigerous cysts in children: a report of 4 cases. J Oral Maxillofac Surg 2001;59(3):331-3.

McCrea S. Adjacent dentigerous cysts with the ectopic displacement of a third mandibular molar and supernumerary (forth) molar: a rare occurrence. Oral Surg Oral Med Oral Pathol Oral Radiol Endod 2009;107(6):5-20.

Medici A, Raho MT, Anghinoni M. Ectopic third molar in the condylar process: case report. Acta Biomed Ateneo Parmense 2001;72(5-6):115-8.

Pace C, Holt D, Payne M. An unusual presentation of an ectopic third molar in the condylar region. Aust Dent J 2010;55(3):325-7.

Salmeron JI, del Amo A, Plasencia J, Pujol R, Vila CN. Ectopic third molar in condylar region. Int J Oral Maxillofac Surg 2008;37(4):398-400.

Sanghera RK, Jones J. Parotid fistula--an extraorally draining infected dentigerous cyst associated with a supernumerary fourth molar in ascending ramus. Dent Update 2013;40(4):343-5.

Scott N, Bater A, Wilson A. An unusual cause of a facial swelling. J Surg Case Rep 2012;2012(10): 10 .

Shivashankara C, Manjunatha BS, Tanveer A. Ectopic mandibular third molar in subcondylar region: report of a rare case. Oral Maxillofac Surg 2012;16(1):153-5.

Suarez-Cunqueiro MM, Schoen R, Schramm A, Gellrich NC, Schmelzeisen R. Endoscopic approach to removal of an ectopic mandibular third molar. $\mathrm{Br} \mathrm{J}$ Oral Maxillofac Surg 2003;41(5):340-2.

Tumer C, Eset AE, Atabek A. Ectopic impacted mandibular third molar in the subcondylar region associated with a dentigerous cyst: a case report. Quintessence Int 2002;33(3):231-3.
Ustuner E, Fitoz S, Atasoy C, Erden I, Akyar S. Bilateral maxillary dentigerous cysts: a case report. Oral Surg Oral Med Oral Pathol Oral Radiol Endod 2003;95(5):632-5.

Wang CC, Kok SH, Hou LT, Yang PJ, Lee JJ, Cheng SJ, et al. Ectopic mandibular third molar in the ramus region: report of a case and literature review. Oral Surg Oral Med Oral Pathol Oral Radiol Endod 2008;105(2):155-61.

Wassouf A, Eyrich G, Lebeda R, Gratz KW. Surgical removal of a dislocated lower third molar from the condyle region: case report. Schweiz Monatsschr Zahnmed 2003;113(4):416-20. 